\title{
Peculiarities in FIB Induced Damage of Diamond
}

\author{
S. Rubanov ${ }^{1}$ and A. Suvorova ${ }^{2}$ \\ ${ }^{1}$ Electron Microscopy Unit, Bio21 institute, The University of Melbourne, Victoria 3010, Australia \\ ${ }^{2}$ Centre for Microscopy, Characterisation and Analysis, The University of Western Australia, Crawley, \\ WA 6009, Australia
}

TEM samples preparation from hard materials, such as diamond is a challenging task using traditional methods of preparation, including mechanical thinning, argon ion milling and chemical etching. It has been demonstrated that a cross-sectional TEM sample from diamond can be relatively easy prepared using FIB milling technique [1]. However, FIB milling has problems, such as FIB-induced damage and Ga-contamination [2-3]. An additional problem for diamond exists due to the possible rearrangement of broken diamond bonds into more stable $\mathrm{sp}^{2}$ bonds. In this work the damage formation during FIB milling of diamond was studied as a function of $\mathrm{Ga}$ ion dose.

To study the initial stages of the damage formation synthetic high-pressure-high temperature (HPHT) single crystal (001) diamond sample was irradiated with $30 \mathrm{keV}$ Ga ions with doses ranging from $2 \times 10^{14}$ to $10^{16}$ ions $/ \mathrm{cm}^{2}$ using FEI Nova 200 FIB system. The sample was carbon coated to reduce charging during TEM specimen preparation. Additionally, rectangular trenches $4 \times 4 \mu \mathrm{m}^{2}$ and $2 \mu \mathrm{m}$ deep were milled in the diamond sample using $100 \mathrm{pA} \mathrm{Ga}$ ion beam current. The near surface regions of the trenches contained two types of damage after FIB milling: the bottom-wall damage where the ion beam was normal to the surface and the side-wall damage where it was at low angle to the trench walls. To protect created damage layers from any alteration during the sample preparation procedure, $\sim 1 \mu \mathrm{m}$ thick $\mathrm{Pt}$ stripes were deposited over the implanted areas using FIB system e-beam deposition process. Crosssectional TEM samples were prepared using lift-out technique [4].

For the lowest implantation dose $\left(2 \times 10^{14}\right.$ ions $\left./ \mathrm{cm}^{2}\right)$ the point defect density was below amorphisation threshold and implanted region remains crystalline. However, local lattice distortion is clearly visible in Weak Beam DF image. For the Ga dose $3 \times 10^{14}$ ions $/ \mathrm{cm}^{2}$ implanted region contains islands of amorphous and crystalline materials between two interfaces of distorted diamond. These layers of distorted diamond are visible in bright-field and WBDF images (Fig. 1a, b). Fig. 1c shows diamond (111) lattice planes inside of implanted layer. The swelling of implanted region was not observed that indicates the same density in implanted layer and bulk diamond. For the dose $4 \times 10^{14}$ ions $/ \mathrm{cm}^{2}$ and above the implanted region became amorphous. EELS examination has shown the presence of both $\mathrm{sp}^{2}$ and $\mathrm{sp}^{3}$ bonding in the damage corresponding to two different chemical states of carbon. The swelling of the amorphous damage layer is seen (Fig 2a). This swelling is related to diamond's $\mathrm{sp}^{3}$ bonds conversion to $\mathrm{sp}^{2}$ bonds with significant decrease in density. Also, the density of the amorphous layers has been determined using a mass balance calculation. The density decreased with ion dose increased, and reached $2.24 \mathrm{~g} / \mathrm{cm}^{3}\left(80 \% \mathrm{sp}^{2}\right)$ for highest dose in this work $\left(1 \times 10^{16}\right.$ ions $\left./ \mathrm{cm}^{2}\right)$. For continues milling (trench) the thicknesses of the amorphous damage layers were measured to be $16 \mathrm{~nm}$ for side-walls and $44 \mathrm{~nm}$ for the bottom-walls (Fig. 2b). The measured thicknesses of the amorphous damage layers are summarised in Fig. 2c. The thickness of the amorphous damage layer exponentially grows with ion dose and has a tendency to saturate at $44 \mathrm{~nm}$ that has been measured for continuous milling. Concentration of implanted $\mathrm{Ga}$ atoms has been estimated to be 20 and 32 at.\% for side-wall and bottom-wall damage layers, respectively. 
The FIB induced damage in diamond comprises amorphous and crystalline components and it combines complex processes of ion penetration, swelling and sputtering during ion implantation in diamond. Amorphisation in diamond results in transition of $\mathrm{sp}^{3}$ bonds to $\mathrm{sp}^{2}$ corresponding to two different chemical states of carbon with density reduction. High concentration of Ga atoms is probably a result of accumulation of implanted atoms in damage layers due to short penetration depth and low sputtering yield in diamond.

References

[1] S. Rubanov, AMTC Letters 2 (2010) p. 104.

[2] J.F. Walker and R.F. Broom, Inst.Phys.Conf.Ser. 157 (1997) p. 473.

[3] S. Rubanov and. P.R. Munroe, J. Microsc. 214 (2004) p. 213.

[4] L.A. Giannuzzi et al., Microsc. Res. Tech. 41 (1998) p. 285.
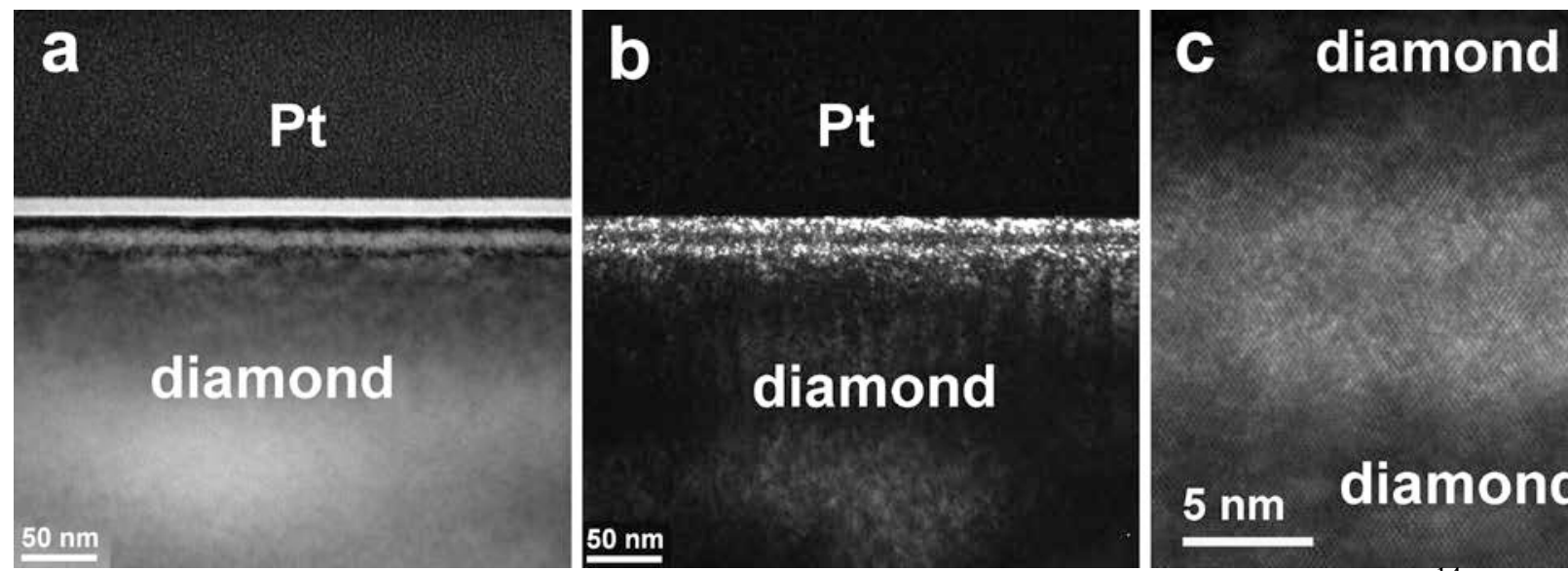

Figure 1. BF (a), WBDF (b) and HREM (c) images of implanted layer with dose $3 \times 10^{14}$ ions $/ \mathrm{cm}^{2}$.
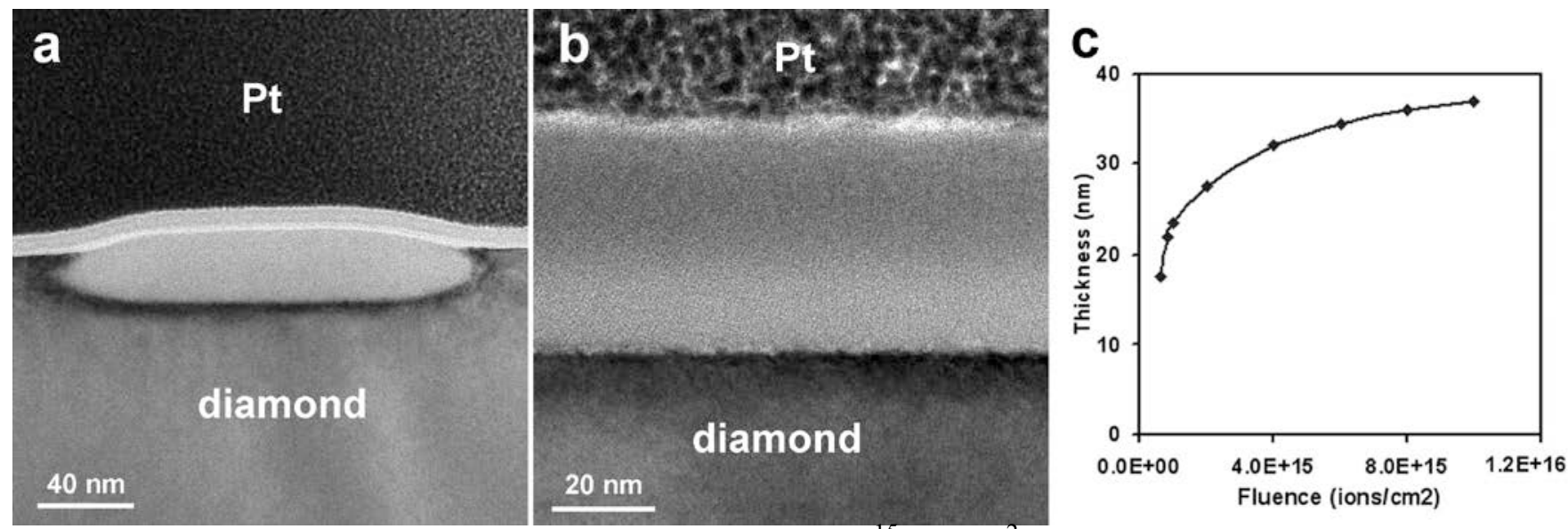

Figure 2. Damage in diamond after implantation of $4 \times 10^{15} \mathrm{Ga} / \mathrm{cm}^{2}$ (a) and continues milling (b); the measured thickness of the amorphous damage layers as a function of the implantation dose. 